\title{
The Liverpool Care Pathway: benefit or harm?
}

\author{
KE Sleeman \\ Clinical Lecturer in Palliative Medicine, Cicely Saunders Institute, Department of Palliative Care, Policy and Rehabilitation, King's College \\ London, London, UK
}

TITLE Liverpool Care Pathway for patients with cancer in hospital: a cluster randomised trial

AUTHORS Costantini M, Romoli V, Leo SD et al

IOURNAL Lancet 2014 383: 226-37. http://dx.doi.org/I0.10I6/S0I40-
6736(I3)6I725-0

DECLARATION OF INTERESTS No conflict of interest declared.

\author{
Correspondence to KE Sleeman \\ King's College London \\ Cicely Saunders Institute \\ Department of Palliative Care, \\ Policy and Rehabilitation \\ Bessemer Road \\ London SE5 9PJ \\ UK
}

e-mail katherine.sleeman@kcl.ac.uk Twitter @kesleeman

\section{SUMMARY}

How do we improve care for the dying in hospital? Around half of all deaths in the UK occur in hospitals and surveys of the bereaved consistently report that the quality of end of life care is poorer in hospitals than hospices. The Liverpool Care Pathway (LCP) was developed in the late 1990s to bridge this gap, and was rapidly promoted as a model of good practice. However, this rapid promotion occurred in the absence of strong evidence of its benefits. What evidence there was came from quasi-experimental (non-randomised) studies, and audits that measured processes of care (e.g. whether opioids were prescribed) but not patient outcomes (e.g. whether patients' pain improved).' This created a Catch22 situation: once the LCP became accepted as a gold standard it was almost impossible to test it in a comparative study.

Therefore it fell to researchers abroad to test the efficacy of the LCP. Costantini et al. performed a multicentre cluster randomised trial in Italian hospitals involving 308 patients with cancer (and their families). ${ }^{2}$ They found no significant difference in their primary endpoint (the overall quality of care toolkit scale) between patients who died on wards where the LCP was being used and those on wards where it was not. Some secondary endpoints, such as feeling treated with dignity, kindness and respect, and breathlessness, did improve in the LCP group. Notably, there was no evidence of harm and no difference in survival between the groups

\section{OPINION}

In the Independent Review of the LCP, convened following media reports linking its implementation with poor care, Julia Neuberger concluded that without strong evidence of its benefits or harms, use of the LCP (in England) could not be justified. ${ }^{3}$ The study by Costantini et al., published six months after the Neuberger Review, provides the first strong evidence: that the LCP does not improve overall quality of care. ${ }^{2}$

Why might the study have found no improvement in overall quality of care? Perhaps this was due to a poor choice of primary endpoint? Or perhaps care of the dying in Italian cancer wards is already good, meaning the LCP had less chance of improving it? Of course, it may be that the LCP simply does not improve care of the dying. Patients in this study spent an average of 31.5 hours on the LCP before they died. How much can we reasonably expect to improve within this timeframe?

The study by Costantini et al. was rigorous and well designed. ${ }^{2}$ But it was underpowered, giving the possibility of a Type 2 error (not finding a difference where one existed). However, the effect sizes were small, suggesting little clinical difference irrespective of statistical significance. An important question is: how generalisable are these findings? For example, do they tell us anything about the potential of the LCP to improve care for people with diagnoses other than cancer? Or in healthcare systems outside Italy? 
The LCP was widely promoted without convincing evidence of its benefits. Is evidence considered less important or relevant when people are dying? All complex interventions will have benefits and harms, some of which will be predictable, others unpredictable. ${ }^{4}$ Testing such interventions in people who are dying is challenging but it is both possible and necessary, as this trial shows.

\section{REFERENCES}

I Sleeman KE, Collis E. The Liverpool care pathway: a cautionary tale. BMJ 2013; 347: f4779. http://dx.doi.org/ I0.I I36/bmj.f4779

2 Costantini M, Romoli V, Leo SD et al. Liverpool Care Pathway for patients with cancer in hospital: a cluster randomised trial. Lancet 2013; 383: 226-37. http://dx.doi.org/l0.10I6/S0I406736(I3)6I725-0
It is essential that we measure the impact of the care we provide to people who are approaching the end of life. For this we need to collect data on clinical outcomes, not just processes, and with a focus on the last weeks and months of life, not just the last hours.

3 Department of Health. More Care, Less Pathway: A Review of the Liverpool Care Pathway. 2013. https://www.gov.uk/government/ uploads/system/uploads/attachment_data/file/2 I 2450/Liverpool_ Care_Pathway.pdf

4 Currow DC, Higginson I.Time for a prospective study to evaluate the Amber Care Bundle. BMJ Support Palliat Care 2013; 3: 376-7. http://dx.doi.org/I0.I I36/bmjspcare-2013-000608

\section{CONFERENCING AND EVENTS}

The Royal College of Physicians of Edinburgh has a unique blend of rooms providing the perfect location for your conference, meeting or event. The Victorian Great Hall, galleried New Library and the Georgian Cullen Suite are wonderful settings for dinners and receptions. The modern Conference Centre seats up to 300 people in raked seating and is complemented by breakout rooms seating from 10 to 150 people, a keypad voting system and video conferencing. The College provides a stunning setting for weddings and receptions and is licensed for both civil and religious ceremonies. Discounts are available for Fellows and Members, medical conferences and charities.

For more information or for a quotation, please contact the Events Team on +44 (0) I3I 225 7324; email events@rcpe.ac.uk or visit http://www.rcpe-venue.co.uk 